unsatisfactory and should be thoroughly overhauled in any reprinting - some have no bibliography at all, sometimes an author is listed but with no journal or date, sometimes a reference made to unpublished work appears alone, and practically all the lists are absurdly short. The manner of presentation leads one to speculate about the kind of reader envisaged, and to the conclusion that the American executives, technical personnel and students, for whom this is written, are no better trained in science than their English counterparts.

W. J. ONIONS

\section{A CATALOGUE OF THE ULTRA-VIOLET}

Organic Electronic Spectral Data

Vol. 1 : 1946-1952. Edited by Mortimer J. Kamlet. Pp. xiv +1208 . 215s. Vol. 2 : 1953-1955. Edited by Herbert E. Ungnade. Pp. $\mathrm{x}+919$. 132s. (New York: Interscience Publishers, Inc.; London : Interscience Publishers, Ltd., 1960.)

THE object of this work is to present all useful published data on the ultra-violet and visible absorptivity of organic compounds. The criterion of usefulness is adequacy to define the molar absorptivity for at least one stated wave-length of maximum absorption. The solvent used, or $p \mathrm{H}$ of an aqueous solvent, is also stated, if known, though the concentration is not; and literature references are given for all entries. Compounds are arranged as a molecular formula index, and the number comprised must be between twenty and thirty thousand, for many of which more than one set of data is supplied. Gasphase measurements are included.

Critical treatment of this material, difficult in view of its great bulk, becomes nearly impossible because of the chaos of modes in which the data have originally been expressed. The editors give candid warning that, despite their best endeavours, a proportion of the figures may thus be out by a factor of ten, or of the molecular weight, or both, and that the reference to the original paper should be followed up in any case of doubt. Within this limitation, absorptions are here uniformly expressed as molar absorptivity, $\log \varepsilon$, where $\varepsilon$ has the value $\log \left(I_{0} / I\right) / c b, c$ being in $\mathrm{cm}$. and $b$ in moles/1. The latter expression is now adopted as the definition of 'extinction coefficient' preferred by the Optical Data Commission of the International Union of Pure and Applied Chemistry. A statement of only two significant figures of the mantissa, however, can be appreciably less precise than the measurement it reports. Thus a figure of $4 \cdot 23$, signifying the range $4 \cdot 225-4 \cdot 234$, would cover (for 0.001 per cent of a solute of molecular weight 300 ) measured extinctions from 0.559 to 0.571 . For quantitative purposes, significance in the third figure is desirable and attainable, and it seems matter for some regret that, in cases where such precision has been recorded, it must be lost in the editorial reduction to two figures.

The search for material in more than seventy journals appears to have been extremely thorough. Other sources - to judge by the omission of, for example, amodiaquine (British Pharmaceutical Codex, 1954), chlorpheniramine (U.S. Pharmacopoeia, 1955) and the chlorosalicylanilides (American Medical Association's Standards for New and Non-official Remedies, 1955)-have not been drawn on.
The choice between systematic and coined names is not always made consistently; for example, "Antazoline" is used, but not "chloroquine" (U.S. Pharmacopoeia, 1955, and Chemical Abstracts Index, 1954), though the latter is an example where the coined name would make for easier reference among the seven entries under its molecular formula.

The numerals in the formulæ of Volume 2 are smaller but sharper than in Volume 1 ; a combination of the best qualities of both would seem ideal. That a work of such enormous scope should realize everyone's ideal in every respect, however, is scarcely conceivable; and the measure achieved here, and promised in the further volumes by which the project will be brought up to date, must claim the gratitude and respect of all users of data of this kind.

E. G. Kellett

\section{EUROPEAN PARASITES OF MAN}

\section{Parasitologie für Ärzte}

Von Prof. Otto Jírovec. Unter Mitarbeit von Dr. J. Jíra, Dr. E. Kmetý, Dr. J. Kramáŕ, Dr. M. Petrủ und Dr. B. Rosicky. Pp. xi +684. (Jena : Gustav Fischer Verlag, 1960.) 93.65 D.M.

7 HERE are, Dr. Jírovec says in his preface, several good books on medical parasitology; but most of these deal more especially with parasites found in man in tropical and subtropical countries and few concentrate on species found in European climates. This book, however, gives more of its space to these, the tropical and subtropical species being relatively briefly described. The emphasis throughout is on bionomics, epidemiology, diagnosis and therapy, less space being given to the clinical signs of parasitic disease.

The chief author, Dr. Jírovec, has written the general account of parasitism (Part 1), the description of parasitological techniques (Part 2) and the sections on the Protozoa (Part 3) and helminthology (Part 4). The section on the Protozoa occupies almost half the book and reflects, in considerable detail, the work of Dr. Jírovec and his colleagues, and many will be glad to have the accounts here given of parasites such as Pneumocystis, Toxoplasma and Trichomonas vaginalis, which are less extensively discussed in other text-books. The section on the arthropods (Part 5), on parts of which Dr. Rosický collaborated, is on the whole less evenly covered. The section on the leptospiroses was written by Dr. Kmetý, the account of Toxoplasma by Dr. Jírovec in collaboration with Dr. Jfra and the sections on the rickettsias, Trichomonas vaginalis and Pneumocystis were revised by Prof. Vaněk, Prof. Peter and Dr. Syrůček respectively. Other collaborators were Dr. Kramár on the Diptera and Dr. Petru on paragonimiasis and ascariasis of the lung.

The book, which is written in clear and simple German, fully maintains the high standard of production of the house of Gustav Fischer. The 285 illustrations are all good and many of them, supplied by the author or his colleagues, are not available in other books. They include useful photographs of helminth eggs and of parasites in the host's tissues, and some of these were taken through the phase-contrast microscope. There are several illustrations in colour, and, although most of these will be helpful to the reader, some of them raise the question, also raised by coloured illustrations in other text-books, whether 